\title{
ЕДИНСТВО РЫНКА ЕС: ДОСТИЖЕНИЯ И ВЫЗОВЫ
}

\begin{abstract}
Аннотация. 2018 г. был ознаменован 25-летием Единого внутреннего рынка Европейского союза (ЕВР). Это стало поводом для активизачии количественных исследований этого фено́мена мировой экономики. Статья основана на официальных документах ЕС по тематике ЕВР и результатах, полученных европейскими центрами компетенции. Критически рассмотрена методика расчёта эффектов ЕВР. На фоне весьма высокой официальной оценки обозначены основные внутренние и внешние вызовы нынешней стадии развития ЕВР.
\end{abstract}

Ключевые слова: единый внутренний рынок, Европейский союз, эффект единого рынка.

Среди официальных публикаций по тематике ЕВР, выпущенных институтами Европейского союза в 2018 г., отметим Сообщение Европейской комиссии от 22 ноября «Единый рынок в меняющемся мире; необходимо сохранить приверженность уникальному активу» ${ }^{1}$. Документ заслуживает внимания за содержащийся в нём ряд посылов на ближайшее будущее. Главный из них обозначен в самом названии - продолжить работу по совершенствованию ЕВР и следовать целям, ради которых этот рынок был построен.

Наряду с неблагоприятными тенденциями, в том числе потерей позиций Евросоюза в глобальной торговле, о которой в сообщении сказано вполне откровенно, отмечается высокая эффективность ЕВР. Она измеряется 8,5\% валового внутреннего продукта Союза. Это самая высокая оценка за всю историю наблюдений ${ }^{2}$ Тем самым официальный Евросоюз утверждает, что эффективность от единства рынков государств-членов не только не снижается, как это может показаться, но, напротив, растёт.

\section{Эффективность ЕВР}

Впервые оценка эффективности ЕВР была дана в 1988 г. в Докладе Чеккини, зам. главы профильного директората. Утверждалось, что выгода от устранения издержек, возникающих из-за непродуктивных остаточных нетарифных барьеров, разделяющих государства Европейского экономического сообщества, составляет 5-6,5\% совокупного ВВП ${ }^{3}$. Показатель был получен путём расчёта сокращения издержек, возникающих от устранения или гармонизации физических, технических и налоговых препятствий на пути передвижения товаров, услуг, капиталов и людей (на тот момент насчитывалось примерно три сотни барьеров).

(C) Кондратьева Наталия Борисовна - кандидат экономических наук, доцент, ведущий научный сотрудник, учёный секретарь ИЕ РАН. Адрес: 125009 , Россия, Москва, ул. Моховая, д. 11, стр. 3. Доцент НИУ «Высшая школа экономики»; заведующая базовой кафедрой европейских и интеграционных исследований Института мировых цивилизаций. E-mail: nkondratieva@inbox.ru.

DOI: http://dx.doi.org/10.15211/vestnikieran120199103107

${ }^{1}$ Single Market in a changing world: A unique asset in need of renewed political commitment . Brussels, 22.11.2018 $\operatorname{COM}(2018) 772$.

${ }^{2}$ Подробный обзор оценок Европейской комиссии и ведущих центров компетенции (RAND Europe (БрюссельКембридж), CEPS (Брюссель), Europe Economics (Лондон), GHK International (Лондон), Bertelsmann Stiftung (Германия) о влиянии ЕВР на экономический рост, занятость, благосостояние, структурные особенности экономик см. в : Zsolt Pataki (2014). The Cost of Non-Europe in the Single Market. «Cecchini Revisited». An overview of the potential economic gains from further completion of the European Single Market. European Parliamentary Research Service. September.

${ }^{3}$ Checchini P., Catinat M., Jacquemin A. The Benefits of a Single Market. Wildwood House. 1988. 
Понятно, что подобные оценки чрезвычайно сложны в деталях, а количество переменных, включаемых в анализ, с годами лишь увеличивается. Так, в последние десятилетия право ЕВР проникло в такие сферы как госзакупки, безотходная экономика, низкоуглеродная, наконец, цифровая экономика. Методика нынешней официальной оценки не конкретизирована. Однако представляется, что она основана на предшествующих исследованиях, дополненных оценкой выгод от перехода на очередные европейские законы.

Главное то, что подход в подобных оценках остаётся неизменным. Эксперты суммируют возможные выгоды для экономик государств - членов ЕС от принятия регламентов и директив ЕВР и европейских технических стандартов, дополняющих или заменяющих национальные, с двух различных сторон - со стороны спроса и со стороны предложения.

Влияние на спрос заключается в том, что потребители получают больше возможностей рассматривать товары и услуги с точки зрения их заменяемости на аналоги из других стран Евросоюза. Наднациональное регулирование ведёт к снижению монопольной власти как отечественных, так и импортных товаров и услуг. В результате, благодаря росту ценовой и качественной конкуренции, увеличивается потребление.

Влияние на предложение заключается в том, что фирма, производящая товары для домашнего рынка и на экспорт в пределах пространства ЕВР, больше не обязана организовывать производство в соответствии с различными технологиями и нести издержки по приобщению к целевым рынкам. Гармонизация стандартов приводит к устранению такого типа издержек и, соответственно, снижению цены товара. Это приводит к повышению общей производительности экономики. Не вызывает возражений также включение в расчёт ожиданий от перераспределения рабочей силы и капитала из менее эффективных в более эффективные юрисдикции, а также от так называемого эффекта оздоровления экономики благодаря перераспределению активов в пользу более эффективных операторов.

Однако в качестве критики официального подхода стоит подчеркнуть, что в расчёт включена не реальная, а именно вероятная выгода от устранения барьеров и выявленных нарушений европейских норм, как и задержек с их принятием со стороны некоторых стран.

Важно учитывать и то, что эффект ЕВР «на выходе» будет меньше из-за затрат «на входе», а именно, затрат на подстройку под наднациональные требования и более жёсткие условия конкуренции. Нельзя также снимать со счетов вероятность исчезновения уникальных товаров, рассчитанных на элитарный платёжеспособный спрос. В современных условиях широкой открытости и наличия на рынках практически всей палитры товаров, массовый потребитель чаще ориентируется на низкую цену и среднее или даже низкое качество. Отсюда, производители уникальной продукции с высокими издержками оказываются в проигрыше, вынуждены подстраиваться под массовое производство. Разнообразие предложения сокращается. Таким образом, возникает необходимость в поддержании предложения путём защиты географических наименований, поощрения НИОКР, а также контроля надлежащего исполнения принципа взаимного признания национальных стандартов и норм. В итоге, цитируемая официальная оценка не безусловна и требует критического осмысления.

\section{Внутренние вызовы}

Несмотря на очевидный рост торговли, передвижения людей капиталов и инноваций, выгоду для экономических акторов от устранения барьеров, выгоды для потребителей от усиления конкуренции, аналитики не снимают с повестки дня вопрос об устойчивости европейской экономики перед внутренними и внешними вызовами. Почему?

Мы уже отметили, что единый рынок требует расходов на его поддержание, а именно, 
на контроль исполнения норм, устранение злонамеренной практики и нормативное обустройство новейших секторов. С одной стороны, основополагающие принципы субсидиарности, пропорциональности, взаимного признания национальных стандартов, норм, практик задают верхний предел развитию наднациональных норм. С другой стороны, объём наднациональных полномочий неуклонно повышается. Количество европейских норм прирастает в среднем на две в месяц (по авторским подсчётам).

Соблюдение же законов ЕВР не является 100\%-ным. Государства-члены независимо от экономического положения зачастую не готовы принять, перенести в национальные законы и реализовать конкретные меры, предложенные Комиссией и согласованные на самом высоком уровне. Даже, когда они выражают политическую поддержку дальнейшей гармонизации, то лукаво запаздывают с продвижением европейских правил, что нередко приводит к судебным расследованиям.

За последние десять лет был достигнут прогресс в транспонировании директив ЕВР. Количество директив, перенос которых в национальное законодательство проходи с задержкой по срокам, сократилось до приемлемого уровня (с 6,3\% в 1997 г. до 0,9\% в 2017 г.). Тем не менее, ЕК видит проблему с надлежащим соблюдением законодательства. Она встревожена фактами несоблюдения сроков транспонирования 16-ти директив, из-за чего произошёл срыв их вступления в силу в период между декабрём 2017 г. и маем 2018 г. На июнь 2018 г. он составил $25 \%$. А по трём директивам о государственных закупках, которые должны были быть перенесены в национальное право к апрелю 2016 г., Комиссия в том же июне 2018 г. обнаружила 58 нарушений в 21 государстве - члене $\mathrm{EC}^{1}$.

Очевидно, нормотворчество вызывает неудобства в догоняющих странах ЦВЕ и стагнирующих странах Юга. ЕВР отнимает у них конкурентные преимущества, заключающиеся в низких издержках и низкой стоимости их товаров и труда. Более того, ЕВР парадоксальным образом бьёт также по состоятельным экономикам, сокращая их шансы на лидерство. И те и другие страны вынуждены проводить политику, которая им перестаёт «нравиться» ${ }^{2}$. Ответный удар по целостности Евросоюза, как известно, уже был нанесён решением о выходе одной из самых благополучных стран-членов - Великобритании. Часть её национальных норм была жёстче европейских, что стало в своё время предметом разбирательств в Суде ЕС.

Лояльность аутсайдеров к нормам ЕВР приходится субсидировать через общий бюджет. Учитывая, что отсутствует заметный прогресс в деле снижения социально-экономических диспропорций ${ }^{3}$, маловероятно, что благополучные страны освободятся от бремени донорства. Британцы всегда были ярыми противниками системы бюджетного перераспределения, принятой внутри Евросоюза, что зачастую вызывало разногласия.

В итоге, общую политику, сопровождающую развитие ЕВР, чаще называют политикой Брюсселя. У государств-членов на поверку оказывается мало общих подходов по этому вопросу. Проблема стран-получателей в том, что сейчас им крайне не хватает аргументов для ответа на вопрос, зачем в них вкладывать средства.

\section{Внешние вызовы}

В последние годы Европейский союз столкнулся сразу с несколькими внешними вызо-

\footnotetext{
${ }^{1}$ Single Market in a changing world: A unique asset in need of renewed political commitment. Brussels, 22.11.2018 COM(2018)772.

${ }^{2}$ Marian L. Tupy. The European Union: A Critical Assessment Cato Institute Economic development bulletin No. 26. June 22, 2016. URL: https://object.cato.org/sites/cato.org/files/pubs/pdf/edb26-revised.pdf.

${ }_{3}$ Subsidiarity and Proportionality in the Single Market. An EU fit for inclusive growth. Bertelsmann Stiftung, 2018. P. 13-19. URL: https://www.copenhageneconomics.com/dyn/resources/Publication/publicationPDF/9/469/1544453164/ subsidiarity-and-proportionality-in-the-single-market.pdf.
} Научно-аналитический вестник ИЕ РАН, 2019, №1 
вами. Во-первых, это ускоренный рост нерегулируемых экономик, свободных от соответствующих расходов. Во-вторых, выбор, который государства-члены всё чаще делают в пользу партнёров за пределами $\mathrm{EC}^{1}$. Рост внерегиональной торговли стал следствием ускоренного развития новых технологий, открывших огромные возможности для снижения издержек на транспорт и связь. В-третьих, заморозка переговоров о Трансатлантическом торгово-инвестиционном партнёрстве. Альянс с США, чья конкурентная стратегия также опирается на экономику знаний и верховенство закона, должен был создать противовес влиянию моделей, опирающихся на социальный демпинг или государственную финансовую поддержку. Однако он не состоялся именно из-за разногласий по методам регулирования экономики.

Европейские политики призывают к объективной оценке стоимости ЕВР. Для этого они предлагают опираться на опыт 1980-х гг. В частности, Марио Драги, Президент ЕЦБ, в докладе на конференции, организованной Школой управления Hertie, Институтом Жака Делора и Фондом Бертельсманна в Берлине 19 сентября 2018 г., напомнил, что благодаря трём компонентам - дальновидности, тщательному анализу и откровенному обсуждению проблем Жак Делор смог преодолеть «фундаментальные различия во мнениях» и «ментальные оговорки» ${ }^{2}$, характерные для политического климата того времени. В то время лидеры сосредоточили внимание на раскрытии и популяризации потенциала европейской интеграции. Упор был сделан на инвентаризации протекционистских барьеров, проникновении интеграции в смежные сферы (например, от отмены виз для граждан государств-членов к признанию их избирательных прав, профессиональных дипломов и пенсионных прав) и развитие вспомогательных учреждений ${ }^{3}$. Без них пользы для потребителей и экономических акторов могло бы и не быть.

Европейские лидеры того времени говорили о низком росте как об общей проблеме и предложили использовать единство рынков как инструмент для её решения. Институты также стремились к тому, чтобы взаимное открытие рынков сопровождалось мерами, обеспечивающими его справедливость. А эти меры в свою очередь ложились пропорциональным бременем на государства и предприятия, для того чтобы сделать безусловными преимущества для граждан, потребителей.

Таким образом, Единому рынку была отведена важная общественная функция по созданию общего жизненного пространства, для которого характерен широкий выбор, высокое качество и доверие к товарам и услугам, которых нет нигде в мире. Тем более важно учитывать, что конкуренцию странам Союза на глобальном уровне могут создать только страны континентального размера.

\section{Выводы}

Мнения об эффективности ЕВР различны. Официальная оценка, которая приведена в статье, - одна из самых высоких за его историю. Этот инструмент активизации конъюнктуры и облегчения торгового обмена не сработал «на все сто» только потому, что его добавочная стоимость частично съедается издержками по соблюдению норм. Однако очевидно, что лидерство в глобальной экономике требует затрат на его поддержание.

Нужно отметить, что в Евразийском экономическом союзе также проводят оценки интеграционных эффектов с помощью количественных методов ${ }^{4}$. По аналогии в них проводится

\footnotetext{
${ }^{1}$ См. статистику, например: John Weeks. Does the EU «single market» foster trade? Prime. June 28. 2018. URL: http://www.primeeconomics.org/articles/does-the-eu-single-market-foster-trade.

${ }_{2}$ Mario Draghi. Economic and monetary union: past and present. Speech. 19.09.2018. URL: https://www.ecb.europa. eu/press/key/date/2018/html/ecb.sp180919.en.html/

3 Stefano Micossi. Thirty Years of the Single European Market. Bruges European Economic Policy Briefings №41, 2016. P. 16.

${ }^{4}$ Оценка экономических эффектов отмены нетарифных барьеров в ЕАЭС - ЦИИ ЕАБР. Доклад №29. 2015. Научно-аналитический вестник ИЕ РАН, 2019, №1
} 
инвентаризация барьеров, мониторинг национальных регуляторных различий, изменений торговых предпочтений государств. Опросы предприятий-экспортёров рассматриваются как дополнительный источник информации. Выводы представляют ценность для исполнительной ветви власти. Тем не менее, учёные также склоняются к точке зрения о том, что эффект единства рынков носит преимущественно качественный характер, а именно, создаёт среду, где есть высокие стандарты, доверие к акторам и безопасность потребления.

\section{References}

Single Market in a changing world: A unique asset in need of renewed political commitment . Brussels, 22.11.2018 COM(2018)772.

Checchini P., Catinat M., Jacquemin A. The Benefits of a Single Market. Wildwood House. 1988.

Mario Draghi. Economic and Monetary Union: Past and Present. Speech. 19.09.2018. URL: https://www.ecb.europa.eu/press/key/date/2018/html/ecb.sp180919.en.html.

Zsolt Pataki. The Cost of Non-Europe in the Single Market. «Cecchini Revisited». An overview of the potential economic gains from further completion of the European Single Market. European Parliamentary Research Service. September, 2014.

Marian L. Тирую The European Union: A Critical Assessment Cato Institute Economic development bulletin №26. 22.06.2016. URL: https://object.cato.org/sites/cato.org/files/pubs/pdf/edb26revised.pdf.

John Weeks. Does the EU «single market» foster trade? Prime. 28.06.2018. URL: http://www.primeeconomics.org/articles/does-the-eu-single-market-foster-trade.

Subsidiarity and Proportionality in the Single Market. An EU fit for inclusive growth. Bertelsmann Stiftung, 2018. P. 13-19. URL: https://www.copenhageneconomics.com/dyn/resources/Publi ca tion/publicationPDF/9/469/1544453164/subsidiarity-and-proportionality-in-the-single-market.pdf.

Stefano Micossi. Thirty Years of the Single European Market. Bruges European Economic Policy Briefings №41, 2016. P. 16.

\section{EU Single Market: Achievements and Challenges}

Author. Natalia Kondratieva, Candidate of Sciences (Economics), Leading Research Associate, Academic Secretary, Institute of Europe, Russian Academy of Sciences. Address: 11-3, Mokhovaya str., Moscow, Russia, 125009. Associate Professor, National Research University Higher School of Economics; Head of the Specialised Department of European and Integration Studies, Institute of World Civilizations. E-mail: nkondratieva@inbox.ru.

Abstract. $25^{\text {th }}$ anniversary of the EU Single market, celebrated in 2018, was the occasion for intensifying of the quantitative research on this phenomenon of the world economy. The paper is based on the EU official documents and the results obtained by the European competence centers. The method of calculating the effects of the EU Single market is critically considered. Against the background of a very high official assessment, the main internal and external challenges of the current stage of Single market development are outlined.

Key words: single market, European Union, single market effect.

DOI: http://dx.doi.org/10.15211/vestnikieran120199103107

URL: https://eabr.org/upload/iblock/8bb/doklad_29_preview.pdf; Оценка влияния нетарифных барьеров в ЕАЭС: результаты опросов предприятий - ЦИИ ЕАБР. Доклад №30. 2015. URL: https://eabr.org/upload/iblock/14f/doklad 30_ntb_2_preview.pdf; Седалищев В.В., Чокаев Б.В., Кнобель А.Ю. Оценка эффектов интеграции ЕАЭС. РАНХ. $20 \overline{17} .33 \mathrm{c}$. 